\title{
VARIABLE EXPONENT SOBOLEV SPACES ASSOCIATED WITH JACOBI EXPANSIONS
}

\section{Víctor Almeida, Jorge J. Betancor, Alejandro J. Castro, Alejandro SANABRia AND ROBERTo SCOTTO}

Abstract. In this paper we define variable exponent Sobolev spaces associated with Jacobi expansions. We prove that our generalized Sobolev spaces can be characterized as variable exponent potential spaces and as variable exponent Triebel-Lizorkin type spaces.

Mathematics subject classification (2010): Primary 42C10, Secondary 42C05, 42C20.

Keywords and phrases: Variable exponent Sobolev spaces, variable exponent potential spaces, Jacobi expansions, spectral multipliers.

\section{REFERENCES}

[1] C. BAlDERRAmA AND W. URBINA, Fractional integration and fractional differentiation for Jacobi expansions, Divulg. Mat., 15 (2007), pp. 93-113.

[2] H. Berens, P. L. Butzer, AND U. WestPhAL, Representations of fractional powers of infinitesimal generators of semigroups, Bull. Amer. Math. Soc., 74 (1968), pp. 191-196.

[3] J. J. Betancor, A. J. Castro, J. Curbelo, J. C. Fariña, And L. Rodríguez-Mesa, Square functions in the Hermite setting for functions with values in UMD spaces, Ann. Mat. Pura Appl. (4), 193 (2014), pp. 1397-1430.

[4] J. J. Betancor, J. C. Fariña, L. Rodríguez-Mesa, R. Testoni, And J. L. Torrea, A choice of Sobolev spaces associated with ultraspherical expansions, Publ. Mat., 54 (2010), pp. 221-242.

[5] J. J. Betancor, J. C. Fariña, L. Rodríguez-Mesa, R. Testoni, and J. L. Torrea, Fractional square functions and potential spaces, J. Math. Anal. Appl., 386 (2012), pp. 487-504.

[6] J. J. Betancor, J. C. Fariña, L. Rodríguez-Mesa, R. Testoni, And J. L. Torrea, Fractional square functions and potential spaces, II, Acta Math. Sin. (Engl. Ser.), 31 (2015), pp. 17591774.

[7] A. Bonami And J.-L. Clerc, Sommes de Cesàro et multiplicateurs des développements en harmoniques sphériques, Trans. Amer. Math. Soc., 183 (1973), pp. 223-263.

[8] B. Bongioanni And J. L. Torrea, Sobolev spaces associated to the harmonic oscillator, Proc. Indian Acad. Sci. Math. Sci., 116 (2006), pp. 337-360.

[9] B. Bongioanni And J. L. Torrea, What is a Sobolev space for the Laguerre function systems?, Studia Math., 192 (2009), pp. 147-172.

[10] M. M. Boureanu, P. PuCCI, AND V. D. RĂDulesCu, Multiplicity of solutions for a class of anisotropic elliptic equations with variable exponent, Complex Var. Elliptic Equ., 56 (2011), pp. 755767.

[11] D. Buraczewski, T. Martinez, J. L. Torrea, And R. Urban, On the Riesz transform associated with the ultraspherical polynomials, J. Anal. Math., 98 (2006), pp. 113-143.

[12] F. CACCIAFESTA AND P. D' ANCONA, Weighted $L^{p}$ estimates for powers of selfadjoint operators, Adv. Math., 229 (2012), pp. 501-530.

[13] A. J. CAStro, A. NOWAK, AND T. Z. SZAREK, Riesz-Jacobi transforms as principal value integrals, J. Fourier Anal. Appl., 22 (2016), pp. 493-541.

[14] Ó. Ciaurri, A. NowaK, AND K. Stempak, Jacobi transplantation revisited, Math. Z., 257 (2007), pp. 355-380. 
[15] W. C. Connett And A. L. Schwartz, A multiplier theorem for Jacobi expansions, Studia Math., $52(1974 / 75)$, pp. 243-261.

[16] D. Cruz-Uribe, A. Fiorenza, J. M. Martell, and C. Pérez, The boundedness of classical operators on variable $L^{p}$ spaces, Ann. Acad. Sci. Fenn. Math., 31 (2006), pp. 239-264.

[17] L. Diening, Maximal function on generalized Lebesgue spaces $L^{p(\cdot)}$, Math. Inequal. Appl., 7 (2004), pp. 245-253.

[18] L. Diening, P. HaRJulehto, P. Hästö, AND M. RŮŽIČKA, Lebesgue and Sobolev spaces with variable exponents, vol. 2017 of Lecture Notes in Mathematics, Springer, Heidelberg, 2011.

[19] L. DiEnING AND M. RŮŽIČKA, Calderón-Zygmund operators on generalized Lebesgue spaces $L^{p(\cdot)}$ and problems related to fluid dynamics, J. Reine Angew. Math., 563 (2003), pp. 197-220.

[20] T. L. Dinu, Nonlinear eigenvalue problems in Sobolev spaces with variable exponent, J. Funct. Spaces Appl., 4 (2006), pp. 225-242.

[21] J. Duonndikoetxea, Fourier analysis, vol. 29 of Graduate Studies in Mathematics, American Mathematical Society, Providence, RI, 2001, Translated and revised from the 1995 Spanish original by David Cruz-Uribe.

[22] X. FAN, Boundary trace embedding theorems for variable exponent Sobolev spaces, J. Math. Anal. Appl., 339 (2008), pp. 1395-1412.

[23] G. Gasper And W. TRebels, Multiplier criteria of Marcinkiewicz type for Jacobi expansions, Trans. Amer. Math. Soc., 231 (1977), pp. 117-132.

[24] P. Harjulehto, P. HÄstö, Ú. V. LÊ, And M. Nuortio, Overview of differential equations with non-standard growth, Nonlinear Anal., 72 (2010), pp. 4551-4574.

[25] R. Hunt, B. Muckenhoupt, And R. Wheeden, Weighted norm inequalities for the conjugate function and Hilbert transform, Trans. Amer. Math. Soc., 176 (1973), pp. 227-251.

[26] R. A. Kerman, Strong and weak weighted convergence of Jacobi series, J. Approx. Theory, 88 (1997), pp. 1-27.

[27] G. Kyriazis, P. Petrushev, And Y. Xu, Jacobi decomposition of weighted Triebel-Lizorkin and Besov spaces, Studia Math., 186 (2008), pp. 161-202.

[28] B. LANGOWS KI, Sobolev spaces associated with Jacobi expansions, J. Math. Anal. Appl., 420 (2014), pp. 1533-1551.

[29] Z. LI, Conjugate Jacobi series and conjugate functions, J. Approx. Theory, 86 (1996), pp. 179-196.

[30] Z. LI, F. SonG, AND K. LI, Characterizations of smoothness of functions in terms of their Jacobi expansions, Results Math., 59 (2011), pp. 13-34.

[31] J.-L. Lions And J. Peetre, Sur une classe d'espaces d'interpolation, Inst. Hautes Études Sci. Publ. Math., (1964), pp. 5-68.

[32] T. MARTINEZ, Multipliers of Laplace transform type for ultraspherical expansions, Math. Nachr., 281 (2008), pp. 978-988.

[33] S. MedA, A general multiplier theorem, Proc. Amer. Math. Soc., 110 (1990), pp. 639-647.

[34] B. Muckenhoupt, Mean convergence of Jacobi series, Proc. Amer. Math. Soc., 23 (1969), pp. $306-$ 310.

[35] B. Muckenhoupt, Transplantation theorems and multiplier theorems for Jacobi series, Mem. Amer. Math. Soc., 64 (1986), pp. iv+86.

[36] B. MucKenhoupt AND E. M. STEIn, Classical expansions and their relation to conjugate harmonic functions, Trans. Amer. Math. Soc., 118 (1965), pp. 17-92.

[37] F. Narcowich, P. Petrushev, And J. WARd, Decomposition of Besov and Triebel-Lizorkin spaces on the sphere, J. Funct. Anal., 238 (2006), pp. 530-564.

[38] A. NowaK AND L. Roncal, Potential operators associated with Jacobi and Fourier-Bessel expansions, J. Math. Anal. Appl., 422 (2015), pp. 148-184.

[39] A. NOWAK AND P. SJÖGREN, Calderón-Zygmund operators related to Jacobi expansions, J. Fourier Anal. Appl., 18 (2012), pp. 717-749.

[40] A. Nowak And P. SJÖgren, Sharp estimates of the Jacobi heat kernel, Studia Math., 218 (2013), pp. 219-244.

[41] A. NOWAK, P. SJÖGREN, AND T. Z. SZAREK, Analysis related to all admissible type parameters in the Jacobi setting, Constr. Approx., 41 (2015), pp. 185-218.

[42] J. L. Rubio de Francia, F. J. Ruiz, And J. L. Torrea, Calderón-Zygmund theory for operatorvalued kernels, Adv. in Math., 62 (1986), pp. 7-48. 
[43] M. RŮŽIČKA AND L. DiEnING, Non-Newtonian fluids and function spaces, in NAFSA 8 - Nonlinear analysis, function spaces and applications, vol. 8, Czech. Acad. Sci., Prague, 2007, pp. 94-143.

[44] S. SAMKO, On some classical operators of variable order in variable exponent spaces, in Analysis, partial differential equations and applications, vol. 193 of Oper. Theory Adv. Appl., Birkhäuser Verlag, Basel, 2009, pp. 281-301.

[45] C. Segovia And R. L. Wheeden, On certain fractional area integrals, J. Math. Mech., 19 (1969/1970), pp. 247-262.

[46] E. M. Stein, Topics in harmonic analysis related to the Littlewood-Paley theory, Annals of Mathematics Studies, no. 63, Princeton University Press, Princeton, N.J., 1970.

[47] K. StempaK, Jacobi conjugate expansions, Studia Sci. Math. Hungar., 44 (2007), pp. 117-130.

[48] G. SzEgô, Orthogonal polynomials, American Mathematical Society, Providence, R.I., fourth ed., 1975, American Mathematical Society, Colloquium Publications, vol. XXIII.

[49] B. WRóBEL, Multivariate spectral multipliers for tensor product orthogonal expansions, Monatsh. Math., 168 (2012), pp. 125-149.

[50] A. Zygmund, Trigonometric series. 2nd ed. Vols. I, II, Cambridge University Press, New York, 1959. 